\title{
The cascade methods of doubly-fed induction machine for generator system
}

\author{
Diep-Dung Nguyen ${ }^{1}$, Ngoc-Hoan Than ${ }^{2}$, Duc-Tuan Hoang ${ }^{3}$ \\ ${ }^{1,3}$ Faculty of Electrical-Electronic Engineering, Vietnam Maritime University, Vietnam \\ ${ }^{2}$ Departement of Electrical Engineering and Automation, Haiphong Private University, Vietnam
}

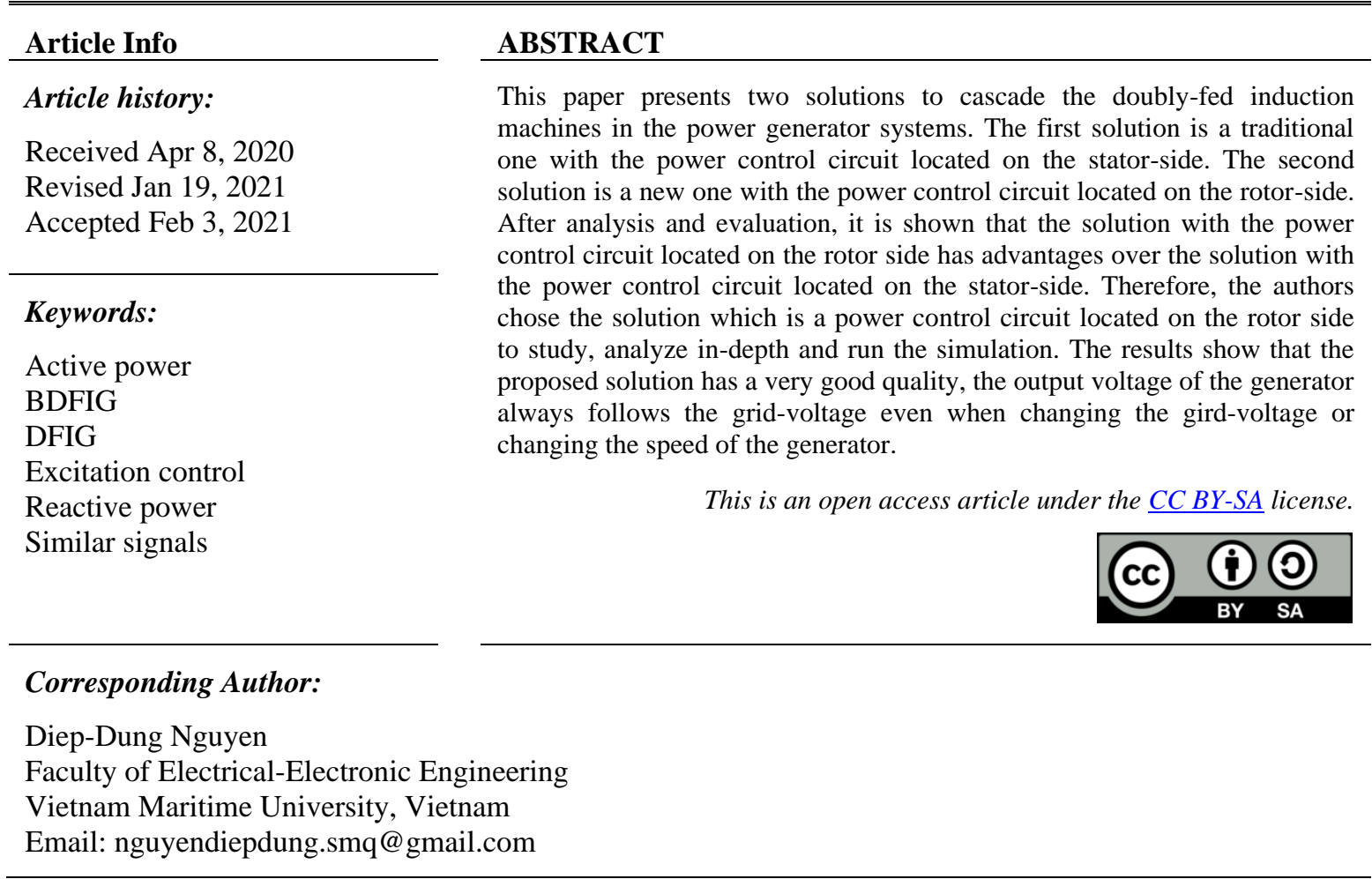

\section{INTRODUCTION}

Nowadays, the resources of fuel are running out, so it is very important and necessary to find and use the renewable sources. These renewable energy sources must be able to connect to the grid or work parallel together [1], [2]. When changing the rotor speed or unstable grid voltage, it is very difficult to control the generator system in order for the generator-voltage coincide with the grid-voltage [3], [4]. The method that uses the doubly-fed induction machine (DFIM) in generator mode is a very effective [5]-[7], because it can keep the stable frequency of the generator-voltage when changing the rotor speed [8]-[10].

The DFIM is an induction machine with both stator and rotor wire [11], [12]. The DFIM worked in the generator mode (DFIG) has inherent advantages, such as the ability to keep the unchanged frequency of the voltage in the case of variable rotor speed, a small control circuit. Therefore, DFIG is widely used in generator systems, such as the wind generator, shaft generator in a ship. In the generator system using DFIG, the power control circuit is located in the rotor-side, and the generated power in the stator-side transmits directly to the grid. Thus, the power of the control circuit is much lower than the power fed into the grid. Some research [13]-[15] have succeeded in controlling DFIG as a generator. The diagram of a power generator system using DFIG is shown in Figure 1.

Stator of DFIG is directly connected to the grid. The rotor of DFIG is connected to the grid via a power control circuit that let the energy can transmit in both directions. There are two working modes of DFIG: the over synchronization mode and the below synchronization mode. In the both modes, the stator generates the energy fed into the grid. The rotor receives the energy in the over synchronous mode and transmits the energy in the below synchronous mode. DFIG as a generator has been increasingly applied in 
practice. However, the technique of controlling DFIG rotor circuits is very difficult [16], especially when the rotor speed changes, the controller must control the frequency of the rotor circuit changes fast and timely in order to synchronize the generator voltage with the grid voltage.

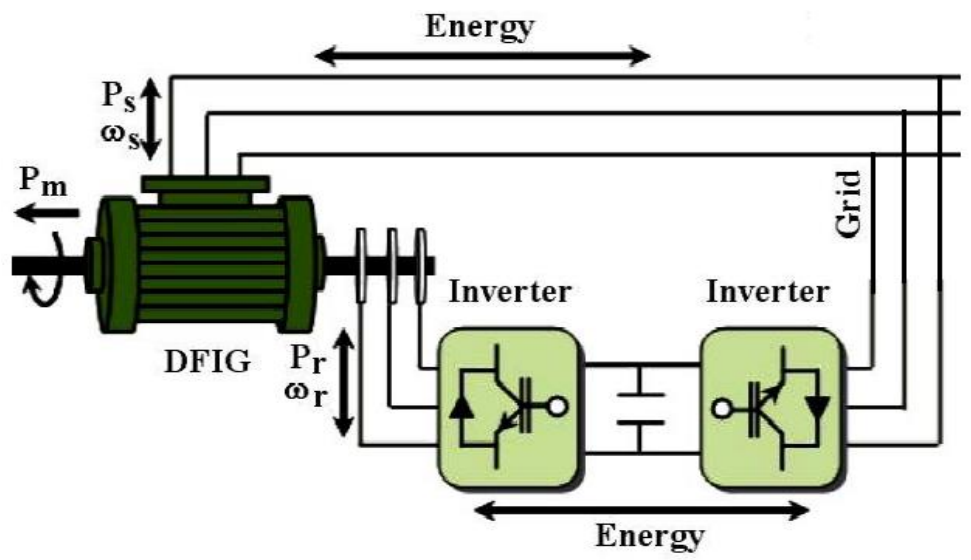

Figure 1. The power generator system using DFIG

A new, effective solution has been proposed which is to use the cascade of two DFIGs. The outstanding advantage of DFIG cascade solution is that the system has the ability to stabilize the frequency of the generator voltage very well when the rotor speed changes. There are two solutions to cascade DFIGs: the first solution is a traditional one with the power control circuit located on the stator-side, the second solution is a new one with the power control circuit located on the rotor-side. This research will analyze the characteristics of two DFIG cascade solutions, then choose the appropriate solution to improve the efficiency of the generator system, study in-depth and simulation the chosen solution.

\section{THE DFIG CASCADE SYSTEM WITH THE POWER CONTROL CIRCUIT LOCATED ON THE STATOR-SIDE}

\subsection{The structure of control system}

The system is described in Figure 2 [17]. The system consists of two DFIGs. Two rotor-shafts are tightly connected together and the electric-wire of two rotors are also directly connected to each other. The power control circuit is located on the stator-side of DFIG1. The electrical power generated in the stator of DFIG 2 is transmitted directly to the grid.

The natural feature of the DFIG cascade system is that the synchronization between the stator voltage of DFIG2 and grid voltage is very high and stable [18]. Furthermore, the quality of DFIG cascade is much better than the generator system using the independent DFIG [19]. Therefore, this system is being applied more and more widely in grid-connected generators. Today, several manufacturing facilities have integrated the DFIG cascade system into the one machine which is called Brushless Doubly-Fed Induction Generator (BDFIG), the diagram of BDFIG is shown in Figure 3 [17].

In Figure 3, the stator of DFIG1 has the number of pole pairs $p_{1}=2$, the stator of DFIG2 has the number of pole pairs $p_{2}=1$. The electric-wire in the rotor of two DFIGs are directly connected together, so this system hasn't a ring and brush. Therefore, this system is called Brushless Doubly-Fed Induction Generator (BDFIG). The BDFIG fabrication techniques are presented in detail in the research [20]. The number of pole pairs of DFIG1 and DFIG2 can be equal or different and there are two ways to connect two electric-wire of rotors, so there are four solutions of integration BDFIG, which are listed in Table 1 [21], [22] 


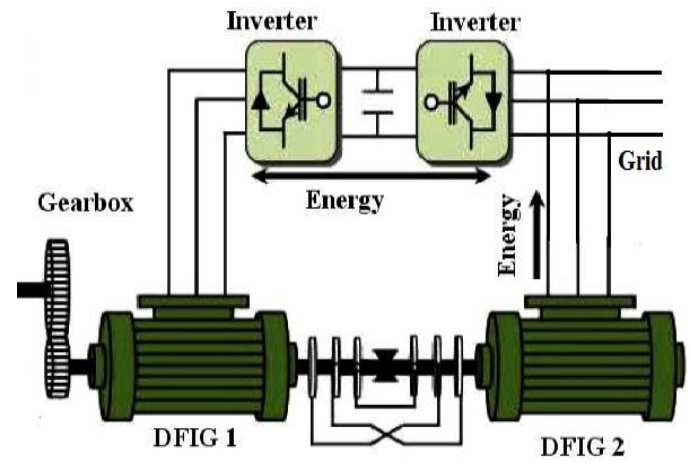

Figure 2. The DFIG cascade system with the power control circuit located on the stator-side

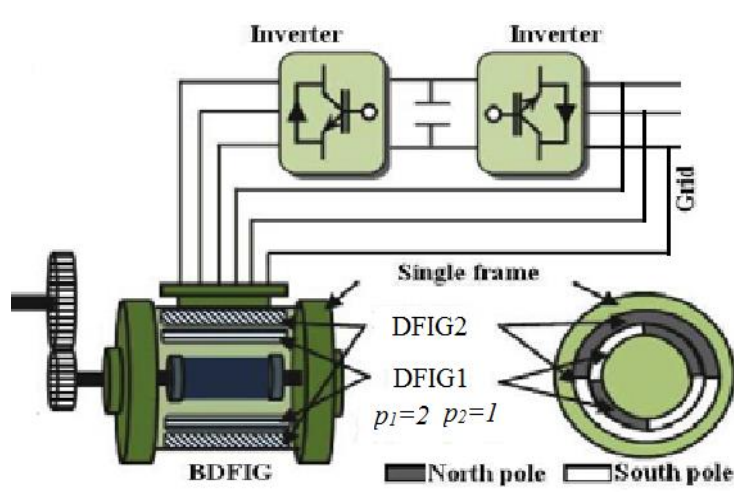

Figure 3. The structure of BDFIG

Table 1. The Types of BDFIG

\begin{tabular}{cccccc}
\hline The connection between two rotors & $p_{1}=p_{2}$ & The sync speed & $P_{s 1}(\mathrm{pu})$ & $P_{s 2}(\mathrm{pu})$ & $P_{g}=P_{s 1}+P_{s 2}$ \\
\hline Similar-phase & Yes & No production & $\frac{p \omega}{\omega_{g}}$ & $\frac{-p \omega}{\omega_{g}}$ & 0 \\
Similar-phase & No & $\frac{-\omega_{g}}{\Delta p}$ & $\frac{p_{1} \omega}{\omega_{g}}$ & $\frac{-p_{2} \omega}{\omega_{g}}$ & $\frac{\Delta p . \omega}{\omega_{g}}$ \\
Reverse phase & Yes & $\frac{\omega_{g}}{2 p}$ & $\frac{-p \omega}{\omega_{g}}$ & $\frac{-p \omega}{\omega_{g}}$ & $\frac{-2 p . \omega}{\omega_{g}}$ \\
Reverse phase & No & $\frac{\omega_{g}}{\sum p}$ & $\frac{-p_{1} \omega}{\omega_{g}}$ & $\frac{-p_{2} \omega}{\omega_{g}}$ & $\frac{-\sum p . \omega}{\omega_{g}}$
\end{tabular}

where $p_{1}, p_{2}$ are the number of polar pairs of DFIG1 and DFIG2 respectively; $P_{s l}, P_{s 2}$ and $P_{g}$ are the active power of DFIG1-stator, DFIG2-stator, and the grid respectively; $\omega$ is the angular speed of the rotor; $\omega_{g}$ is the angular speed of the grid-voltage.

The operation principle of BDFIG is shown in Figure 4 [17]. The stator current frequency of DFIG1 and DFIG2 are $f_{s 1}, f_{s 2}$ respectively; the stator current angular speed of DFIG1 and DFIG2 are $\omega_{s 1}, \omega_{s 2}$ respectively; the rotor current angular speed of DFIG1 and DFIG2 are $\omega_{r 1}, \omega_{r 2}$ respectively.

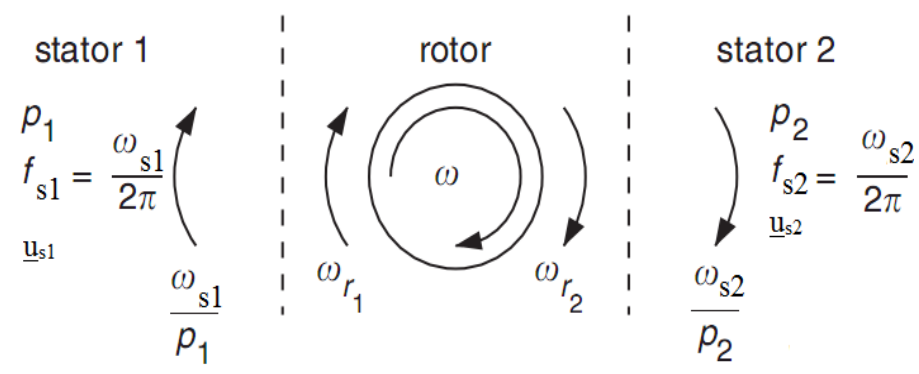

Figure 4. The principle of operation of BDFIG

\subsection{The energies in the system}

Considering a BDFIG type with the number of pole pairs is different, connecting method in the rotor is reverse-phase. Since DFIG2 is directly connected to the grid, the angular speed of the stator circuit is equal to the angular speed of the grid voltage $\omega_{s 2}=\omega_{g}$.

The angular speed of the stator circuit of DFIG1 is:

$$
\omega_{s 1}=\left(p_{1}+p_{2}\right) \cdot \omega-\omega_{s 2}
$$


The angular speed of the rotor circuit of DFIG1 and DFIG2 are:

$$
\begin{aligned}
& \omega_{r 2}=\omega_{s 2}-p_{2} . \omega \\
& \omega_{r 1}=p_{1} . \omega-\omega_{s 2}
\end{aligned}
$$

The stator power of DFIG1 and DFIG2 are:

$$
\begin{aligned}
& P_{s 1}=\frac{-p_{1} \cdot \omega}{\omega_{g}} \cdot P_{g} \\
& P_{s 2}=\frac{-p_{2} \cdot \omega}{\omega_{g}} \cdot P_{g}
\end{aligned}
$$

The rotor power of DFIG1 and DFIG2 are:

$$
\begin{aligned}
& P_{r 1}=-P_{s 1} \frac{\omega_{r 1}}{\omega_{s 1}} \\
& P_{r 2}=-P_{s 2} \frac{\omega_{r 2}}{\omega_{s 2}}
\end{aligned}
$$

The rotor of DFIG1 and DFIG2 are connected into the loop, so $P_{r 1}+P_{r 2}=0$ or $P_{r 1}=-P_{r 2}$. The generated power of BDFIG into the grid is $P_{g}$ :

$$
P_{g}=P_{s 1}+P_{s 2}
$$

From (4)-(7), we have the relationship equation between the power stator of DFIG1 and DFIG2 are as follows:

$$
P_{s 1}=-P_{s 2} \frac{\omega_{s 1}}{\omega_{s 2}}
$$

As shown in (9) also shows the relationship between the power of the control circuit and the power transmitted into the grid. In fact, there is also a power loss in the stator and rotor of DFIG1 and DFIG2, the energy flow diagram is shown in Figure 5 [17], [18].

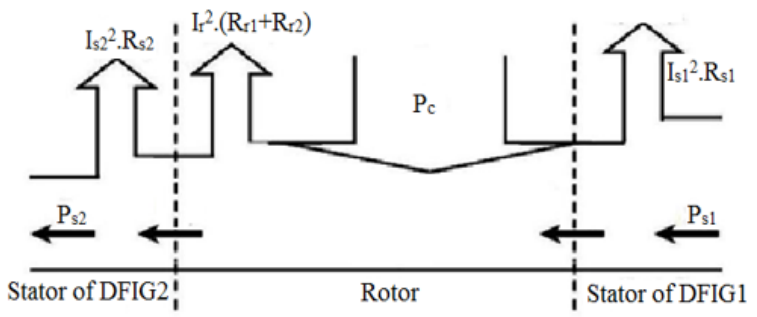

(a)

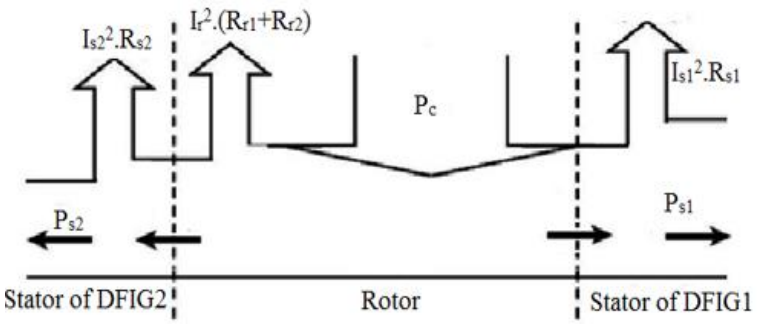

(b)

Figure 5. The energy flow diagram in BDFIG; a) super_synchronous, b) sub_synchronous

According to the energy diagram, DFIG2 always generates active power, DFIG1 generates active power in the over synchronous mode and absorbs the active power in the below synchronous mode. When we connect the rotor wire by reverse phase method, the energy flowed through DFIG1 stator in the opposite direction: DFIG1 absorbs active power in the over synchronous mode and generates active power in the below synchronous mode. 
The research [23] has compared the quality of the generated electric between BDFIG and DFIG. The results showed that the power generator system using BDFIG has higher quality than a system using DFIG. However, the drawback of the BDFIG system is that its large size and greater power loss compare with DFIG. To overcome this limitation, another solution to cascade DFIGs is proposed that is the solution with a power control circuit located on the rotor side. This solution has reduced size, little power loss, simple control system, etc.

\section{THE DFIG CASCADE WITH THE POWER CONTROL CIRCUIT LOCATED ON THE STATOR-SIDE}

\subsection{The structure and operating principle}

The structure of DFIG cascade with the power control circuit located on the stator-side is shown in Figure 6. The system includes two DFIG1 and DFIG2 with the same number of pole pairs $p_{1}=p_{2}=p$, the processing signal stages and the current control circuit. The stator of DFIG1 is connected directly to the grid so the angular speed of the stator circuit of DFIG1 $\left(\omega_{s 1}\right)$ is equal to the angular speed of grid voltage: $\omega_{s 1}=\omega_{g}$

The angular speed of the rotor circuit of DFIG1 $\omega_{r 1}=\omega_{s 1}-p . \omega$. This angular speed is kept constant through the signal processing stage and the current control circuit, so the angular speed of the rotor circuit of DFIG2 is $\omega_{r 2}=\omega_{r 1}=\left(\omega_{s 1}-p . \omega\right)$.

The angular speed of the stator circuit of DFIG2 is $\omega_{s 2}=p \cdot \omega+\omega_{r 2}=p . \omega+\left(\omega_{s 1}-p . \omega=\right.$ $\omega_{s 1}=\omega_{g}$. Therefore, the angular speed of the stator circuit of DFIG2 $\left(\omega_{s 2}\right)$ is always equal to the angular speed of the grid voltage $\left(\omega_{g}\right)$, and is independent to the angular speed of rotor $(\omega)$. With this nature properties, the system has the ability to follow the grid voltage very well and sustainably. In the system structure, DFIG1 does not have the role of generating power fed into the grid but only creating the signals in the rotor which is the input of the signal processing stage. Therefore, DFIG1 can be selected as a small size and capacity DFIG to reduce the power loss, cost and size of the system.

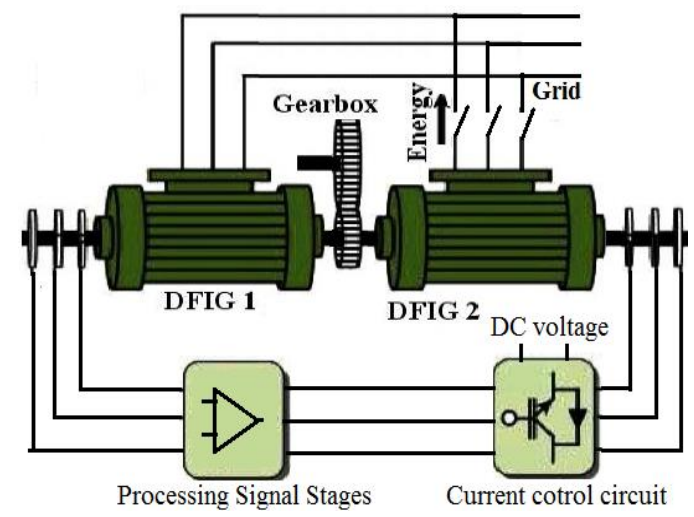

Figure 6. The structure of DFIG cascade with the power control circuit located on the stator-side

\subsection{The control system}

The detailed block diagram of the control system is shown in Figure 7 [24]. The system includes:

- DFIG1 is a small Doubly-Fed Induction Generator, its stator is connected directly to the grid, its rotor works in the high resistance mode. The role of DFIG1 is to create the similar signal voltage in the rotor.

- The similar an isolation stage is a signal amplification circuit with the resistance input is high in order for the rotor of DFIG1 works in the high resistance mode.

- The integral stage

- The signal amplification stages $K_{p}, K_{q}$ and the invert stage (-1).

- The rotation stage of 90 degrees

- The current control circuit creates the current fed into the rotor of DFIG2.

- DFIG2 is a Doubly-Fed Induction Generator with the role of generating the current fed into the grid

The rotor-shaft of DFIG1 and DFIG2 are rigidly connected together in order for the angular coordinates of the rotor wire and stator wire are equal. 


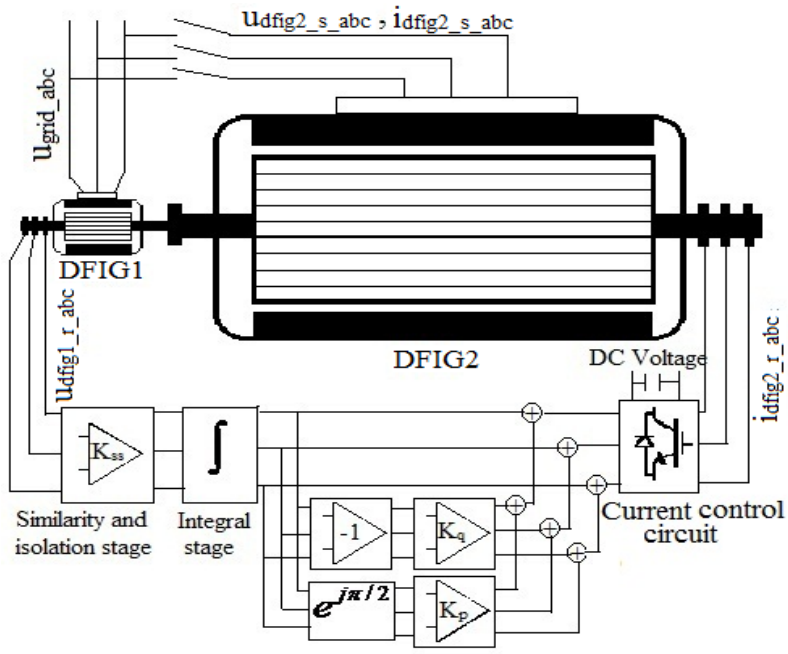

Figure 7. The control system with the power control circuit located on the stator-side

\subsection{Controlling the system}

With the case of the stator of DFIG2 is not connected to the grid, the phase and frequency of the stator voltage of DFIG2 are always equal to the ones of grid voltage. The voltage amplitude of DFIG2 stator depends on the coefficient $\left(K_{c l}\right)$ in the similar an isolation stage [24]. Therefore, the voltage amplitude of DFIG2 stator can be adjusted by adjusting the coefficient $K_{c l}$. After adjustment, Generator voltage has the phase, amplitude and frequency equal to the ones of the grid voltage. This is a good conditional for connecting the generator system to the grid.

With the case of the stator of DFIG2 is connected to the grid, the active power and the reactive power of DFIG2 $\left(P_{s 2}, Q_{s 2}\right)$ are proportional to the amplification coefficients $K_{P}, K_{q}$ [24] respectively:

$$
\left\{\begin{array}{l}
P_{s 2}=K_{p} \cdot X \\
Q_{s 2}=K_{q} \cdot Y
\end{array}\right.
$$

where $X, Y$ is constant values and do not depend on the rotor speed, but only on the structure of DFIG1 and DFIG2. Therefore, the active power and reactive power of DFIG2 $\left(P_{s 2}, Q_{s 2}\right)$ transmitted to the grid can be independently controlled by adjusting the coefficients $K_{p}, K_{q}$.

The research [25], [26] has analyzed the mathematical model of this system, then pointed out the advantages of applying this system in the generator connected to the grid. To show more detail the operating principle and the characteristics of the signals at all stages, we will build and simulate the system model on Matlab Simulink. DFIG1 and DFIG2 are Asynchronous Machine in the Sim-Power-System library with the following parameters in Table 2:

Table 2. The parameters of DFIG1 and DFIG2

\begin{tabular}{lclllllll}
\hline & $\mathrm{P}(\mathrm{VA})$ & $\mathrm{U}(\mathrm{V})$ & $\mathrm{f}(\mathrm{HZ})$ & $\mathrm{Rs}(\Omega)$ & $\mathrm{Ls}(\mathrm{H})$ & $\operatorname{Rr}(\Omega)$ & $\mathrm{Lr}(\mathrm{H})$ & $\mathrm{Lm}(\mathrm{H})$ \\
\hline DFIG1 & 200 & 600 & 60 & 0.0198 & $6.7 \mathrm{e}-4$ & 0.0189 & $6.9 \mathrm{e}-4$ & 0.0339 \\
DFIG2 & 100000 & 600 & 60 & 0.0160 & $5.8 \mathrm{e}-4$ & 0.0168 & $6.7 \mathrm{e}-4$ & 0.0419 \\
\hline
\end{tabular}

\section{RESULTS AND DISCUSSION}

\subsection{In the case of the generator system is not connected to the grid}

The process of adjusting $K_{c l}$ is shown in Figure 8. The voltage of A-phase in the stator of DFIG2 $\left(u_{s 2 a}\right)$ has the frequency and phase always coincides with the ones of A-phase voltage $\left(u_{g}\right)$ of the grid. The amplitude of $u_{s 2 a}$ can be controlled by adjusting the coefficient $K_{c l}$. At time t $=0.7 \mathrm{~s}$, setting $K_{c l}=11.4$, then the voltage $u_{s 2 a}$ is equal to the grid voltage in amplitude, phase, and frequency. This is a good condition to connect the generator system to the grid. 

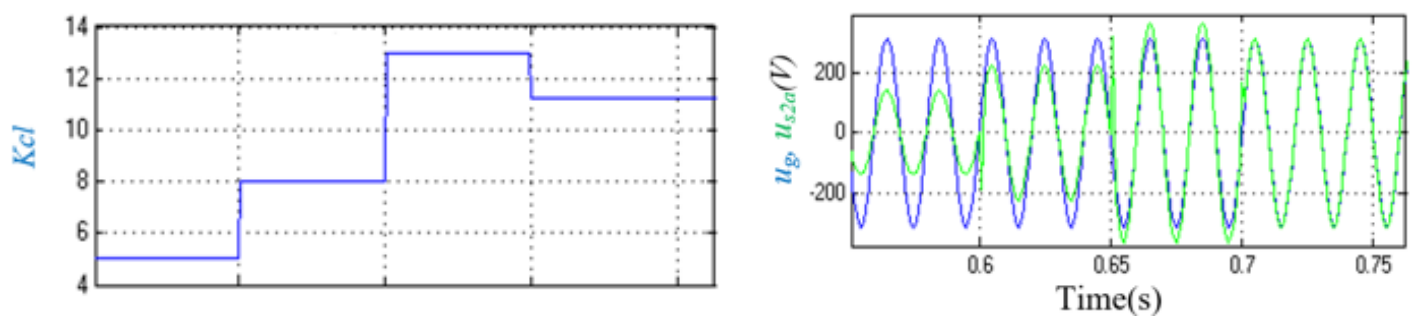

Figure 8. The process of adjusting $K_{c l}$

When changing the rotor speed, the response of the system is shown in Figure 9(a). The results show that the voltage of A-phase in the stator of the generator $\left(u_{s 2 a}\right)$ always coincides with the A-phase voltage of the grid $\left(u_{g}\right)$ in amplitude, frequency and phase. Therefore, the ability to follow the grid voltage of the generator DFIG2 is very good when the rotor speed changes.

When the grid voltage drops, the response of the system is shown in Figure 9(b). The results show that the voltage of A-phase in the stator of the generator $\left(u_{s 2 a}\right)$ always coincides with the A-phase voltage of the grid $\left(u_{g}\right)$ in amplitude, frequency and phase. Therefore, the ability to follow the grid voltage of the generator DFIG2 is very good when the grid voltage changes. Therefore, in the case of stator DFIG2 is not connected to the grid, after adjustment $K_{c l}$, the voltage of the generator system always follows the grid voltage even when the rotor speed changes or the grid voltage changes. This is a good condition to connect the generator system to the grid.

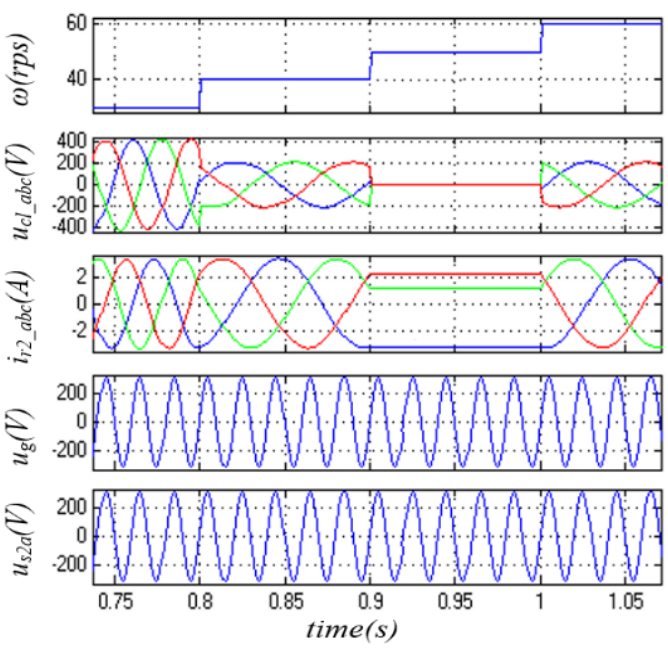

(a)
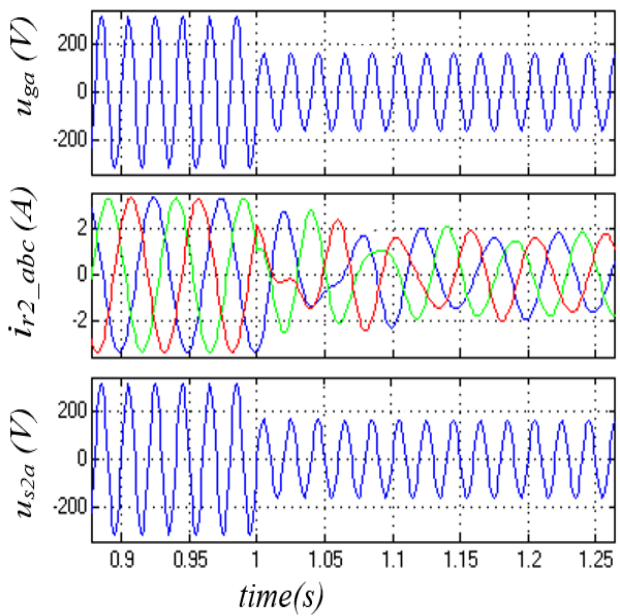

(b)

Figure 9. The response of the system: (a) when changing the rotor speed; (b) when changing the grid voltage

\subsection{In the case of the generator system is connected to the grid}

With the case of generator system is connected to the grid, the response of the system is shown in Figure 10. The results show that it is possible to independently control the active and reactive power of DFIG2 transmitted to the grid by adjusting the coefficients $K_{p}$ and $K_{q}$. The active power depends only to the coefficient $K_{p}$. The reactive power depends only to the coefficient $K_{q}$. Therefore, controlling the active and reactive power of DFIG2 transmitted to the grid will be very simple and convenient. From the above results, it shows that the DFIG cascade system with the power control circuit located on the rotor-side is very suitable for application in the generator with variable rotor speed. 


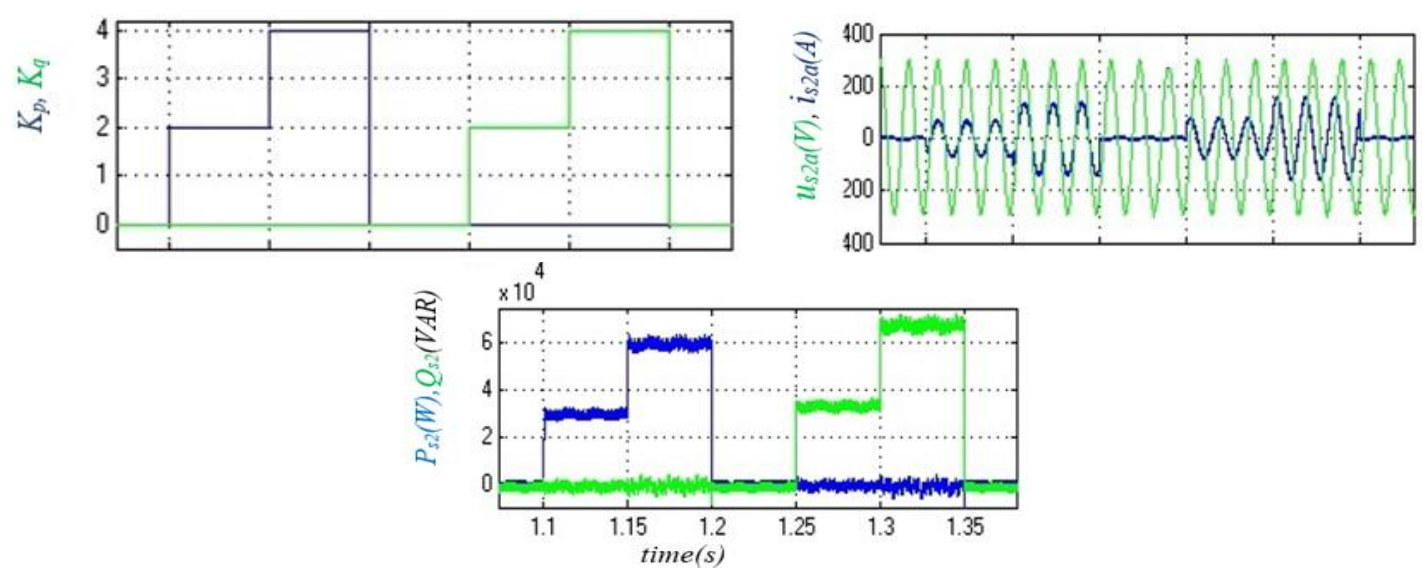

Figure 10. The response of the system when $K \mathrm{p}$ and $\mathrm{Kq}$ change

\section{CONCLUSION}

The paper presented and analyzed the grid-connected generator structures using DFIG cascade solutions, then shown the advantages of applying DFIG cascade solutions in generator system, especially the cascade solution with the power control circuit located in the rotor.

The solution of cascade DFIG with the power control circuit at the rotor side has the following outstanding advantages: The ability to follow the grid voltage is very good, even when the grid voltage changes or the rotor speed changes; The active power and reactive power of the generator fed into the grid are independently controlled through coefficients KP and Kq; The simple system control system structure. In the future, the authors will study more in-depth the solution with the power control circuit located on the rotor-side and apply this system in the real generator systems.

\section{REFERENCES}

[1] Rana, M. M., Li, L., \& Su, S. W., "Controlling the renewable microgrid using semidefinite programming technique," International Journal of Electrical Power \& Energy Systems, vol. 84, pp. 225-231, 2017.

[2] Rana, M. M., Li, L., \& Su, S. W., "Distributed dynamic state estimation over a lossy communication network with an application to smart grids," 2016 IEEE 55th Conference on Decision and Control (CDC), Las Vegas, NV, 2016, pp. 6657-6662.

[3] Xia, K., Zhang, Z., Wang, N., \& Zhang, P., "Operation control and simulation research of the variable-speed constant-frequency system of the ship shaft generator," 2016 IEEE Region 10 Conference (TENCON), Singapore, 2016, pp. 301-304.

[4] Gao, J. M., Wan, S. M., \& Liu, L. L., "The research of marine shaft generator system based on brushless doublyfed machine," 2014 17th International Conference on Electrical Machines and Systems (ICEMS), Hangzhou, 2014, pp. 151-155.

[5] Sankaraiah, M., Reddy, S. S., \& Kumar, M. V., "GWO Based Optimal Reactive Power Coordination of DFIG, ULTC and Capacitors," Indonesian Journal of Electrical Engineering and Computer Science, vol. 11, no. 3, pp. 805-813, 2018.

[6] Mahieddine, H., Zarour, L., Lamri, L., \& Lokmane, N. A., "Developing a grid-connected DFIG strategy for the integration of wind power with harmonic current mitigation," International Journal of Electrical \& Computer Engineering (IJECE), vol. 9, no. 5, pp. 3905-3915, 2019.

[7] Jose, J. T., \& Chattopadhyay, A. B., "Modeling of the magnetizing phenomena of doubly fed induction generator using neuro-fuzzy algorithm considering non-linearity," International Journal of Electrical \& Computer Engineering (IJECE), vol. 9, no. 1, no. 23-33, 2019.

[8] Jeman, A. A. B., Hannoon, N. M., \& Misrin, I., "Small Signal Fault Analysis for Renewable Energy (Wind) Power System Distributed Generation by Using MATLAB Software (Simulink)," Indonesian Journal of Electrical Engineering and Computer Science, vol. 5, no. 3, pp. 401-408, 2017.

[9] Bouderbala, M., Bossoufi, B., Lagrioui, A., Taoussi, M., Aroussi, H. A., \& Ihedrane, Y., "Direct and indirect vector control of a doubly fed induction generator based in a wind energy conversion system," International Journal of Electrical and Computer Engineering (IJECE), vol. 9, no. 3, pp. 1531-1540, 2018.

[10] Phan, D. C., \& Trinh, T. H., "Maximum power extraction method for a doubly-fed induction generator wind turbine," International Journal of Electrical and Computer Engineering (IJECE), vol. 8, no. 2, pp. 711-722, 2018.

[11] Bodson, M., "Speed Control for Doubly Fed Induction Motors with and Without Current Feedback," IEEE Transactions on Control Systems Technology, vol. 28, no. 3, pp. 898-907, 2020.

[12] Soufi, Y., Bahi, T., Lekhchine, S., \& Dib, D., "Performance analysis of DFIM fed by matrix converter and multi level inverter," Energy conversion and management, vol. 72, pp. 187-193, 2013. 
[13] Quang, N. P., Dittrich, A., \& Lan, P. N., "Doubly-fed induction machine as generator in wind power plant: nonlinear control algorithms with direct decoupling," 2005 European Conference on Power Electronics and Applications, Dresden, 2005, pp. 1-10.

[14] Bhowmik, S., Spee, R., \& Enslin, J. H., "Performance optimization for doubly fed wind power generation systems," IEEE Transactions on Industry Applications, vol. 35, no. 4, pp. 949-958, 1999.

[15] Mahrous, A., Metwaly, M. K., \& Elkalashy, N., "Performance investigation of multi-level inverter for DFIG during grid autoreclosure operation," International Journal of Power Electronics and Drive Systems (IJPEDS), vol. 10, no. 1, pp. 454-462, 2019.

[16] F Mahalakshmi, R., Viknesh, J., Vignesh, M. R., \& Thampatty, K. S., "Fuzzy Logic based Rotor Side Converter for constant power control of grid connected DFIG," 2016 IEEE International Conference on Power Electronics, Drives and Energy Systems (PEDES), Trivandrum, 2016, pp. 1-6.

[17] Tir, Z., Rajeai, H., \& Abdessemed, R., "Analysis and vector control of a cascaded doubly fed induction generator in wind energy applications," Revue des Energies Renouvelables SMEE', vol. 10, pp. 347-358, 2010.

[18] Patin, N., Monmasson, E., \& Louis, J. P., "Modeling and control of a cascaded doubly fed induction generator dedicated to isolated grids," IEEE Transactions on industrial electronics, vol. 56, no. 10, pp. 4207-4219, 2009.

[19] Gowaid, I. A., Abdel-Khalik, A. S., Massoud, A. M., \& Ahmed, S., "Ride-through capability of grid-connected brushless cascade DFIG wind turbines in faulty grid conditions-a comparative study," IEEE Transactions on Sustainable Energy, vol. 4, no. 4, pp. 1002-1015, 2013.

[20] McMahon, R. A., Roberts, P. C., Wang, X., \& Tavner, P. J., "Performance of BDFM as generator and motor," IEE Proceedings-Electric Power Applications, vol. 153, no. 2, pp. 289-299, 2006.

[21] Adamowicz, M., \& Strzelecki, R., "Cascaded doubly fed induction generator for mini and micro power plants connected to grid," 2008 13th International Power Electronics and Motion Control Conference, Poznan, 2008, pp. $1729-1733$.

[22] Camocardi, P., Battaiotto, P., \& Mantz, R., “Autonomous BDFIG-wind generator with torque and pitch control for maximum efficiency in a water pumping system," International journal of hydrogen energy, vol. 35, no. 11, pp. $5778-5785,2010$.

[23] A. Gowaid; Ayman S. Abdel-Khalik; Ahmed M. Massoud; Shehab Ahmed, "Ride-Through Capability of GridConnectedBrushless Cascade DFIG Wind Turbines in Faulty Grid Conditions-A Comparative Study," IEEE Transactions on Sustainable Energy, vol. 4, no. 4, pp. 1002-1015, 2013.

[24] Trong, T. N., Tien, B. N., \& Thanh, H. N., "A novel method for excitation control of DFIG connected to the grid on the basis of similar signals from rotor," Applied Mechanics and Materials, vol. 336-338, pp. 1153-1160, 2013.

[25] Trong, T. N., Tien, B. N., \& Thanh, H. N., "Excitation control system of DFIG connected to the grid on the basis of similar signals from rotor," 2013 IEEE International Conference on Mechatronics and Automation, Takamatsu, 2013, pp. 738-742.

[26] Nguyen, T. T., "A rotor-sync signal-based control system of a doubly-fed induction generator in the shaft generation of a ship," Processes, vol. 7, no. 4, p. 188, 2019. 